\title{
Pleistocene divergence of two disjunct conifers in the eastern Australian temperate zone
}

James R.P. Worth ${ }^{1}$, Shota Sakaguchi², Peter A. Harrison ${ }^{3,4}$, Anna Brüniche-Olsen ${ }^{5}$, Jasmine K. Janes ${ }^{6}$, Michael Crisp ${ }^{7}$ and David M.J.S Bowman ${ }^{3}$

${ }^{1}$ Department of Forest Molecular Genetics and Biotechnology, Forestry and Forest Products Research Institute, 1 Matsunosato, Ibaraki 305-8687, Japan.

${ }^{2}$ Graduate School of Human and Environmental Studies, Kyoto University, YoshidaNihonmatsu-cho, Sakyo-ku, Kyoto 606-8501, Japan.

${ }^{3}$ School of Natural Sciences, University of Tasmania, Private Bag 55, Hobart, Tas. 7001, Australia.

${ }^{4}$ Australian Research Council Training Centre for Forest Values, University of Tasmania, Private Bag 55, Hobart, Tas. 7001, Australia.

${ }^{5}$ Department of Forestry \& Natural Resources, Purdue University, West Lafayette, IN 47905, USA. ${ }^{6}$ School of Environmental and Rural Science, University of New England, Armidale, NSW, Australia, 2351

${ }^{7}$ Research School of Biology, The Australian National University, Canberra, ACT, 2601, Australia

Corresponding Author: J.R.P. Worth

jrpw2326@affrc.go.jp

Keywords Disjunct distributions, internal transcribed spacer, temperate conifer, chloroplast DNA, species distribution modelling, molecular dating. 


\begin{abstract}
The eastern Australian temperate biota harbours many plants with fragmented geographic ranges distributed over 1000s of kilometres, yet the spatial genetic structure of their populations remains largely unstudied. In this study, we investigated genetic variation in the nuclear internal transcribed spacer (ITS) and chloroplast DNA sequences to disentangle the phylogeography of two widely distributed but highly fragmented eastern Australian firesensitive temperate conifers: Callitris oblonga (12 populations and 121 individuals) and $C$. rhomboidea (22 populations and 263 individuals). The three highly disjunct populations of $C$. oblonga all had unique chloroplast and ITS haplotypes consistent with the classification of these three populations as distinct subspecies. Molecular dating indicates that divergences of these populations occurred pre- to mid- Pleistocene (2.66 to 1.08 mya). Callitris rhomboidea showed greater diversity of chloroplast haplotypes which was strongly phylogeographically structured $(G s t=0.972)$, with haplotypes unique to specific geographic regions. ITS haplotype diversity was far higher than in C. oblonga with 38 haplotypes displaying high geographic structuring $(G s t=0.387)$ with many population-specific haplotypes. A phylogeographic break was identified between populations north and south of eastern Victoria dated at 0.43-0.45 mya. In both species, the strong genetic structuring of both chloroplast and ITS haplotypes provides evidence that their widespread ranges have resulted from long term persistence in low fire frequency refugia combined with poor dispersal. Any loss of populations due to increasing fire frequency or habitat loss is likely to result in a reduction of genetic diversity.
\end{abstract}




\section{Introduction}

The eastern Australian temperate zone covers over two thousand kilometres latitudinally, extending north from Tasmania to southeastern Queensland and as far west as southeastern South Australia (Olson et al., 2001) (Figure 1). This area encompasses a topographically diverse landscape that, combined with large variability in annual rainfall, supports a diverse range of vegetation types including dry grasslands, sclerophyll woodlands, wet Eucalyptus forests, temperate rainforests, and alpine vegetation types. Transitions between contrasting vegetation types (e.g. forest and grassland) occur at coarse scales and are mainly driven by changes in regional climate, however, such transitions can also occur at much finer scales owing to local edaphic differences, fire history, and microclimates.

During the cooler and drier glacial periods (hereafter 'glacials') that occupied around 85\% of the last approximate one million years (Hope, 1994), ending after the Last Glacial Maximum (LGM; 22,000 to 19,000 years ago; Yokoyama et al., 2000), the environment of the eastern Australian temperate zone was greatly different than present. Temperatures were between 5 to 8 degrees cooler than today (Colhoun, 2000; Williams et al., 2009), with development of ice caps in parts of Tasmania and Mt Kosciusko in south-eastern New South Wales (NSW). Rainfall was around half of the present values, with the arid and semi-arid zones expanding well beyond their present limits (Thom et al., 1994). There is also evidence that fire was less frequent in the landscape than present with lower vegetation biomass (Mooney et al. 2011). The vegetation was relatively open as evidenced by significant aeolian activity which extended into areas that are now well forested, and frost-action formed palaeo-deposits from the LGM occurring down to sea level (McIntosh et al., 2012). Fossil pollen records show that in southern Australia (including the island of Tasmania) large areas were covered in a treeless steppe vegetation that has no exact analogue in the modern vegetation (Hope 1978; D’Costa et al. 1989).

The isolated temperate eastern Australia region is highly distinct from other temperate floras of the world (Cox, 2001) and encompasses six of the twelve plant endemism centres of Australia (Crisp et al., 2001). Many forest species have distributions spanning across most of the temperate zone (i.e. across 1,000-2,000 km), which transgress major biogeographic barriers such as Bass Strait, the Hunter Valley and the southern transition zone in southeastern NSW (Chapple, Keogh, \& Hutchinson, 2005; Milner et al., 2015). Phylogeographic studies of widespread wet forest species within the eastern Australian temperate zone have revealed that they persisted close to their current range in microrefugia during glacials (Byrne 
\& Moran, 1994; Nevill et al. 2010; Worth et al., 2011; Worth et al., 2010; Milner et al., 2012). However, dry adapted temperate species have been relatively poorly studied, and there exist conflicting hypotheses as to their response to the glacial-interglacial cycles. Firstly, it has been hypothesised that such species contracted their ranges and persisted in coastal regions of NSW, south-east Queensland, and western Tasmania, which is supported by pollen reconstructions (Hope et al., 2004) (Figure 1). Under this scenario the southern part of the modern temperate zone of South Australia, Victoria, and eastern Tasmania was dominated by a treeless glacial steppe type vegetation. However, in parts of eastern Tasmania, pollen and genetic evidence supports the survival of temperate dry forest during the LGM (Colhoun \& Shimeld, 2012; Harrison et al., 2014), suggesting that localised refugia for temperate species may have occurred within the dominant steppe type vegetation. A second hypothesis is that temperate, dry adapted species were in fact able to expand their distributions during the glacials, a process which has been well documented in cold tolerant Northern Hemisphere biota (Kearns et al., 2014). However, any such expansions may have remained undocumented by the relatively sparse glacial pollen record of eastern Australia.

This study investigates the phylogeography of two widespread conifers, Callitris oblonga and C. rhomboidea, which are endemic to dry adapted forests of the eastern Australian temperate zone. These two species have the most disjunct ranges of any species in the genus (Bowman, 1995), with Callitris oblonga comprising three disjunct meta-populations across $1500 \mathrm{~km}$ from northern NSW to Tasmania, while C. rhomboidea has a fragmented range across 2100 $\mathrm{km}$ from southeast Queensland to Tasmania with an isolated occurrence in the temperate zone of South Australia (Figure 1c). Both species have poor dispersal, with seed only dispersing one or two tree heights from the parent tree, although the mostly riverine $C$. oblonga may undergo seed dispersal via water and possibly reproduce vegetatively by detached stems (Harris \& Kirkpatrick 1991b). Both species are highly drought tolerant, occurring in the most drought-prone regions in Tasmania (Harris \& Kirkpatrick 1991b). The fragmented distribution of both of these species likely reflects historical events together with their restriction to topographic or climatic niches that afford protection from fire. However, little is known about the distribution of these species during the Pleistocene glacials owing to the poor representation of pollen records from drier regions and the inability to identify pollen below the genus level in Callitris (Luly, 1995), with interpretations of Callitris fossil pollen records complicated by the fact that there are nine species on the Australian mainland that have overlapping ranges with C. oblonga or C. rhomboidea (Bowman, 1995). 
In this paper, we used genetic variation of both nuclear and chloroplast DNA, molecular dating using a Bayesian approach and species distribution modelling to investigate the factors underlying the species' widespread but fragmented ranges. This combined molecular and modelling approach has been shown to be a powerful approach to uncovering the histories of species in the absence of an informative fossil pollen record (Premoli et al. 2010). Our specific aims were to (i) understand patterns of genetic diversity across the range of both species; (ii) determine whether the geographic distribution of each species is a legacy of longterm persistence in multiple glacial refugia in both the northern and southern temperate zones or whether most of the species modern ranges have been colonized in the postglacial from few refugia; (iii) use Bayesian based molecular dating to gain an understanding of the timing of divergence of the major genetic lineages in each species. A particular focus is given to the most southern occurrences of both species in eastern Tasmania. These disjunct populations have an uncertain origin with recent dispersal across the submerged Bassian Plain during glacials (Hill \& Orchard, 1999), as has hypothesised for a suite of plant species that are shared between mainland and eastern Tasmanian dry forests, or survival in local glacial refugia both plausible.

\section{Materials and Methods}

The species

Callitris oblonga is a shrub to small tree up to $10 \mathrm{~m}$ tall (Harris\& Kirkpatrick 1991b) that is mostly confined to riparian areas, however, it can occur in well drained soils above the flood zone and away from rivers, and is even known to occur in coastal dunes (Harris \& Kirkpatrick 1991a). The species is ideally suited to riparian habitats by possessing flexible stems, having a strong lateral root system, and an apparent ability to recover from flood damage clonally (Harris \& Kirkpatrick 1991b). The species occurs in three geographically separated regions in eastern Australia: eastern Tasmania, the Corang River in south-eastern NSW, and the Northern Tablelands of NSW (Figure 1c). The three disjunct meta-populations have been recognised as distinct subspecies due to differences in female cone morphology (Hill, 1998). However, morphological differences between the three meta-populations may be due to plasticity in response to contrasting present climates (Wahid et al., 2006; Xu et al., 2016), and no molecular study has yet resolved their genetic affinities. In Tasmania, $C$. oblonga subsp. oblonga is confined to the drier central and eastern parts of the state (-41.5 to $42.0^{\circ} \mathrm{S}$ ), and mostly occurs along rivers where it is known to occur in 28 discrete populations with an estimated 10,000 mature individuals remaining (Threatened Species Section 2016). 
Callitris oblonga subsp. corangensis occurs only in the upper Corang River in the Southern Tablelands of NSW $\left(-35.2^{\circ} \mathrm{S}\right)$, while Callitris oblonga subsp. parva occurs along a few rivers at altitudes above $1000 \mathrm{~m}$ from the Hastings River $\left(-31.2^{\circ} \mathrm{S}\right)$ to Boonoo Boonoo River (28.8 S) (Nadolny, Llewellyn, \& Benson, 1993; Hunter, 1999).

Callitris rhomboidea is a tree up to $30 \mathrm{~m}$ tall (Harris \& Kirkpatrick 1991b) and often occurs in places affording fire protection such as boulder fields, cliffs or southern aspects (Harris \& Kirkpatrick 1991b; Hahs et al. 1999). Callitris rhomboidea is distributed from the Blackdown Tableland in central Queensland south to southern Tasmania and west to Kangaroo Island and the Mt Lofty Ranges in South Australia (Figure 1c). The species occupies a broad ecological range from sand dunes in the semiarid regions of western Victoria and South Australia, offshore islands and coastal areas, in rocky areas/southern slopes within heathlands and Eucalyptus forests, and even in rainforest (Brown \& Duncan 1986; Harris \& Brown 1980; Harris \& Kirkpatrick 1991a). Despite such extensive latitudinal and altitudinal ranges (0-1250 m) it is relatively uniform in its leaf morphology (Farjon, 2005).

The two species have ranges that come into close proximity in some regions but they only occur in mixed stands in some parts of Tasmania (Harris \& Kirkpatrick 1991b) and northern NSW (M. Crisp personal observation). No verified records of hybridisation between these two species have been reported, which is likely attributed to the mostly allopatric ranges, non-overlapping phenologies (Harris \& Kirkpatrick 1991b) and their distant genetic relationship (M. Crisp personal communication)

Sampling for molecular study

A total of 121 samples of Callitris oblonga from 12 populations were collected, with an average of 10 samples per population (Figure 2 and Supporting Information 1, Table S1). These populations represented all three subspecies as classified by Hill (1998) including seven populations of C. oblonga subsp. oblonga from eastern Tasmania, subsp. corangensis from its single known locality along the Corang River in south-eastern NSW, and four populations of subspecies parva from northern NSW. For C. rhomboidea, a total of 263 individuals were sampled from 22 populations, with an average of 12 samples per population (Figure 2 and Supporting Information 1, Table S2). Nine populations were from Tasmania (including two from Flinders Island), three from Victoria, two from South Australia, three from NSW, and four from southeast Queensland including the most northern population at 
the Blackdown Tablelands. For both species, samples were collected at least one tree height apart to limit the chance of collecting closely related individuals.

\section{Molecular Methods}

Three chloroplast fragments, $t r n \mathrm{H}-p s b \mathrm{~A}, p s b \mathrm{~T}-p s b \mathrm{~N}$ and $r p l 16$ were amplified using PCR (Supporting Information 1, Table S3). In addition, the internal transcribed spacer (ITS) was amplified using the forward primer CY1 TACCGATTGAATGATCCGGTGAAG and the reverse primer CY3 CGCCGTTACTAGGGGAATCCTTGT (Wright, Keeling, \& Gillman, 2006). Both chloroplast and ITS markers are paternally inherited in Callitris (Sakaguchi et al. 2014). Chloroplast and ITS fragments were amplified using the following PCR thermocycle: initial denaturation at $94^{\circ} \mathrm{C}$ for $3 \mathrm{~min}, 35$ cycles of $94^{\circ} \mathrm{C}$ for $1 \mathrm{~min}, 60^{\circ} \mathrm{C}$ for $1 \mathrm{~min}$ and $72^{\circ} \mathrm{C}$ for $1 \mathrm{~min}$, followed by an extension step of $72^{\circ} \mathrm{C}$ for $7 \mathrm{~min}$. All PCR reactions were performed in a total volume of $10 \mu \mathrm{l}$ containing $1 \mathrm{uL} 10 \mathrm{xExTaq}$ buffer; $0.8 \mathrm{uL}$ of $2.5 \mathrm{mM}$ dNTPs; 1uL of 2uM for each primer; 0.05uL of ExTaq DNA polymerase; 2uL of 5xTBTPAR solution (Samarakoon, Wang, \& Alford, 2013) and c. 10 ng of genomic DNA. In preparation for DNA sequencing, PCR products were purified using ExoSAP-IT PCR Product Cleanup enzyme (Affymetrix). For C. rhomboidea, DNA sequencing was performed using the forward primer for all three chloroplast fragments. For C. oblonga, the forward primer was used for psbB-psbH and rpl16 while the trnH-trnA fragment was sequenced in both directions because of a microsatellite region. For both species, the ITS fragment sequencing was performed in both directions using an additional internal primer 5.8SGYM GATGATTCACGGGATTCTG (Pye, Gadek, \& Edwards, 2003) and samples with singleton mutations sequenced twice. Sequences were aligned in Geneious 9.15 using the Geneious alignment algorithm and visually checked for accuracy. ITS sequences of Callitris rhomboidea were phased using DNAsp5 (Rozas \& Rozas, 1995) while C. oblonga was found to have no heterozygous bases.

\section{Phylogeographic analyses}

To determine whether the ITS and chloroplast haplotypes of both C. oblonga and $C$. rhomboidea were monophyletic, we undertook a phylogenetic analysis using samples from the whole Callitris genus (for detailed description of methods and results see Supporting Information 2). Due to a high diversity of ITS haplotypes in C. rhomboidea $(n=38)$, and greater within population haplotype diversity than either the chloroplast data in both species or the ITS in C. oblonga, geographical structure was assessed using isolation-by-distance and 
spatial analysis of molecular variance (SAMOVA) (Dupanloup, Schneider, \& Excoffier, 2002) implemented in Spads 1.0 (Dellicour \& Mardulyn, 2014). SAMOVA is based on a simulated annealing procedure that aims to maximize the proportion of total genetic variance as a result of differences between groups of populations $\left(\mathrm{F}_{\mathrm{CT}}\right)$ resulting in the identification of groups of populations $(K)$ that are geographically homogenous and maximally differentiated from one another (Dupanloup et al., 2002). Isolation-by-distance was assessed using a Mantel test in GenAlex 6.5 and used the DNA sequence-based measure of population differentiation (Phi-PT). In addition, the genetic diversity and divergence of $C$. rhomboidea populations were mapped using the inverse distance weighting interpolation tool in Quantum GIS 3.0.1. These results were interpolated within polygons constructed from point distribution data using the concave hull method (Moreira \& Santos, 2007). Genetic diversity was estimated in Contrib 1.02 (Petit, Mousadik, \& Pons, 1998) which calculated four genetic measures: (i) haplotype richness ( $\mathrm{Hr}$ : rarefied by subsampling to the smallest sample size minus 1, (ii) haplotype diversity (Hk), (iii) absolute genetic differentiation (Dgst), and (iv) contribution to genetic divergence $(c d)$. Median-joining haplotype networks were constructed in Network 5.0 (Bandelt, Forster, \& Röhl, 1999) for both chloroplast and ITS haplotypes of $C$. oblonga and C. rhomboidea. For this analysis, a 5 bp reversal in the trnH-psbA chloroplast fragment in C. rhomboidea was removed because it was demonstrated homoplasy, having evolved independently a minimum of 3 times based on the haplotype network (results not shown).

\section{Molecular dating of major clade divergence times}

To determine the divergence time for the major clades within the two Callitris species we used a multi-locus coalescent analysis for inference of species trees implemented in STARBEAST2 v2.4.7 (Heled \& Drummond 2009). Firstly, the best fitting substitution models for the chloroplast and ITS datasets separately were found using bModelTest (Bouckaert \& Drummond 2017) implemented in STARBEAST2 v2.4.7. We selected from 88 candidate models allowing for rate heterogeneity and a proportion of invariable sites using default settings - Yule clock model and $10^{7}$ iterations. The log files were checked for high ESS values (>200) in TRACER v1.6.0 (Rambaut et al. 2016). The major genetic groups observed in both species were used as priors in our STARBEAST2 (Supporting Information 1, Table S4). For C. oblonga this corresponded to the three subspecies, C. oblonga subsp. oblonga, C. oblonga subsp. corangensis and C. oblonga subsp. parva, and for C. rhomboidea the south and north populations which represented the biggest genetic divide detected using 
SAMOVA. We used a 'birth-death' tree model, the substitution models inferred by bModeltest, a strict clock, and a linear population model with a constant root. Divergence date between $C$. oblonga and C. rhomboidea has been previously estimated as being between 21.2 mya (15.9 - 27.4 mya 95\% HPD) and 23.7 mya (17.9 - 30.0 mya 95\% HPD) (M. Crisp personal communication), both were used as priors but in two separate analyses referred to as “younger” and "older” divergence dates, respectively. For each analysis, a MCMC of $5 \times 10^{7}$ iterations with sampling for every $2 \times 10^{4}$ states were used, with the first $10 \%$ of the MCMC runs discarded as burn-in. Convergence of each model was assessed using TRACER to ensure adequate mixing of the multiple MCMC chains. The chains were combined in LOGCOMBINER and the final phylogeny was visualized in FIGTREE v1.4.2 (Rambaut 2012), and topological uncertainty was visualized in DENSITREE2 v2.2.6 (Bouckaert \& Heled 2014).

Species distribution modelling under current and Last Glacial Maximum climates The distribution of suitable habitat for C. oblonga and C. rhomboidea was modelled as a function of climate and topography using 448 (C. oblonga) and 1533 (C. rhomboidea) occurrence records undertaken with the Random Forest (RF) algorithm (Breiman, 2001) using the randomForest package (Liaw \& Wiener, 2002) in R (see Supporting Information 3 for further details). We grew 1000 regression trees to classify the distribution of suitable habitat for each species using a balanced number of presences to pseudo-absences, where pseudo-absences were randomly sampled across the environmental space of temperate Australia (Figure 1a).

Contemporary (average of the period between1960-1990) climate surfaces were obtained from WorldClim version 1.4 (Hijmans et al., 2005) at a spatial resolution of 30 seconds (ca. 1 $\mathrm{km}^{2}$ grids) and included 19 temperature and precipitation bioclimatic variables (Xu \& Hutchinson, 2013). Standardised climate values were extracted for each species’ occurrence record and a principal component analysis (PCA) applied to identify the key climate gradients across each species distribution (e.g. combination of climate variables with strongest loadings with a single PC axis) using the 'prcomp' function in R (version 3.3.2, $\mathrm{R}$ Core Team 2016; R Core Team, 2017) following Costa Silva et al. (2018). Historic bioclimatic surfaces representing the climate for the Last Glacial Maximum (ca. 22 kya BP) were obtained for three global circulation models (CCSM4, MIROC-ESM, MPI-EMS-P) from WorldClim at a spatial resolution of 2.5 minutes (ca. $5 \mathrm{~km}^{2}$ grids). In addition to climate, 
five topographic features derived from a 30 second ETOPO1 Global Relief Model (https://www.ngdc.noaa.gov/mgg/global/global.html) were generated using the 'terrain' function of the raster package (Hijmans et al., 2017) and included altitude, slope (degrees), aspect (degrees), topographic roughness index (TRI), and topographic position index (TPI) (See Table 1 in Supplementary material S3 for description of variables). The same five topographic features were also estimated for the LGM assuming a $120 \mathrm{~m}$ depression in current sea levels by setting raster values in the ETOPO1 Global Relief Mode less than $120 \mathrm{~m}$ as missing.

The optimised RF model was predicted onto the contemporary environmental surfaces (see above) to produce a spatial probability layer of habitat suitability for Callitris using the raster package. This model was spatially evaluated by first estimating the percent of occurrence records correctly classified, then by quantifying the over-prediction of the model by comparing the area of predicted contemporary suitable habitat to the area currently occupied by each species within a convex $\alpha$-hull calculated using an $\alpha=0.1$ and the 'ahull' function of alphahull (Pateiro-López \& Rodriguez-Casal, 2010). The same model was then used to predict the distribution of suitable habitat for Callitris during the LGM by creating an 'agreement habitat suitability surface' which is a surface representing the average prediction of the three LGM models for a grid cell being suitable habitat for a species.

\section{Results}

Callitris oblonga genetic diversity and structure

All C. oblonga ITS and chloroplast haplotypes formed a monophyletic clade (Figure S1 and Figure S2). For C. oblonga, the aligned ITS sequence was a total of 1112 bp in length with a total of 10 SNPs and two indels defining four phased haplotypes (Genbank Accession numbers: MH280024-27) with strong overall genetic differentiation $(G s t=1)$. The aligned length of the concatenated chloroplast was 1381 bp (trnH-psbA (MH280065-67) = 379 bp, $p s b \mathrm{~T}-p s b \mathrm{~N}(\mathrm{MH} 280068-70)=464$ and rpl16 $(\mathrm{MH} 280083-85)=538)$ with a total of two SNPs and four indels defining three haplotypes and Gst equal to 1. The three haplotypes corresponded with the subspecies classification. However, unlike the ITS based haplotype network, the most diverged haplotype network was found in subspecies corangensis (Figure $4)$. 
Each of the major disjunctions in the species range, corresponding with subspecies classification, harboured a single ITS or chloroplast haplotype apart from the northern subspecies parva which contained two ITS haplotypes differing by five mutations (Figure 3). These two parva haplotypes formed a clade that was diverged from subspecies oblonga and subspecies corangensis by 4 mutations. The Tasmanian and subspecies corangensis from the southern Tableland of NSW samples differed by 2 mutations only.

Callitris rhomboidea genetic diversity and structure

Genetic diversity was higher in C. rhomboidea than C. oblonga at both the ITS and chloroplast (Table 1). All C. rhomboidea ITS and chloroplast haplotypes formed a monophyletic clade (Supporting Information 2, Figure S1 and Figure S2). For C. rhomboidea the aligned ITS sequence was a total of 1185 bp in length with total of 40 SNPs and two indels defining 38 phased haplotypes (Genbank Accession numbers: MH280028-64). Of the 40 SNPs identified, a total of 38 were heterozygous in at least one individual while none of the indels were heterozygous. SAMOVA supported two groups with the highest genetic differentiation $\left(\mathrm{F}_{\mathrm{CT}}=0.806\right)$ separating all populations in Tasmania, Flinders Island, South Australia, and western Victoria from populations in eastern Victoria to Blackdown Tablelands. The haplotypes were highly geographically structured (Gst $=0.387$ ). Haplotype 1 was widespread and was found at high frequency in all 13 populations sampled in Tasmania, western Victoria, and South Australia, whereas haplotype 18 was observed from eastern Victoria to the most northern population in the Blackdown Tablelands (Figure 5). A range of haplotypes were found to be restricted to specific geographic regions, such as haplotype 2 in Tasmania and southern Flinders island, haplotype 19 in Flinders Island, haplotype 7 in South Australia and western Victoria, haplotypes 33 and 34 in northern NSW and haplotypes 23, 24 and 27 in south-eastern Queensland. Twenty-three haplotypes were observed in only one population each. There was a highly significant relationship between pairwise population genetic differentiation and geographic distance $\left(R^{2}=0.4808, \mathrm{P}<0.001\right.$; Supporting Information 1, Figure S3), indicating that genetic structure was associated with isolation-bydistance.

The highest ITS haplotype diversity and rarefied haplotype richness were observed in coastal south-eastern Queensland and the Little Desert in western Victoria, with moderate levels of haplotype richness in Tasmania and central NSW (Supporting Information 1, Figure S1). In 
contrast, South Australian and some NSW populations (Dorrigo and Burrewarra Point) had relatively low ITS diversity but were the most diverged populations.

The aligned length of the concatenated chloroplast was 1483 bp (trnH-psbA (MH319790-95) $=416$ bp, psbT-psbN $(\mathrm{MH} 280071-76)=466$, rpl16 $(\mathrm{MH} 280077-82)=601)$ with a total of 7 SNPs and 3 indels defining six haplotypes and geographic structuring was high with overall $G s t=0.97$. Nearly all populations were fixed for one haplotype except for two in eastern Tasmania (Rocky Rivulet and Cape Tourville) (Figure 6). A clade diverged from other all other C. rhomboidea haplotypes by five mutations was restricted to South Australia/ western Victoria (haplotype 6) and Flinders Island (haplotype 5). Haplotype 4 was widespread and the only haplotype observed from southern NSW to Blackdown Tableland while a population in eastern Victoria near Mallacoota was fixed for a closely related haplotype (haplotype 3). Tasmanian haplotypes (haplotype 1 and 2) were diverged by 4 polymorphisms from the most closely related haplotype.

\section{Molecular dating}

The best fitting substitution models were HKY for cpDNA and TN93 for ITS. There was high support for all nodes in the tree (range: 91\% to 100\%; Table 2). Divergence times for the Callitris subspecies ranged between $0.43-2.45$ mya for the younger prior and $0.47-2.66$ mya for the older prior with the $C$. rhomboidea being more recently diverged than the $C$. oblonga subspecies (Table 2; Figure 7). There was a small degree of uncertainty in topology among the C. oblonga subspecies as shown by the alterative red and green topologies (Supporting Information 1, Figure S2).

\section{Current and Last Glacial Maximum modelled ranges}

The habitat suitability models derived through Random Forest were able to relate the known contemporary distribution of C. rhomboidea and C. oblonga with both climate and topography. The low out-of-bag error rate (C. rhomboidea, 3.6\%; C. oblonga, 1.7\%) and high Gini Index (C. rhomboidea, 0.93; C. oblonga, 0.97) suggests that the models could differentiate pseudo-absences from true presence records. Indeed, all C. oblonga distribution points and $80 \%$ of $C$. rhomboidea distribution point's occupied areas predicted to be of suitable habitat (Figure 8a, c). In the latter case, populations of $C$. rhomboidea occupying the margin of its known distribution range tended to be more poorly predicted by the model than central core populations. However, there was a general tendency for the models to overpredict the area of contemporary suitable habitat especially in Tasmania and NSW. 
The Random Forest models predicted extensive areas of suitable habitat for both species during the LGM along the eastern coastline of mainland Australia and eastern Tasmania as well as along the southern coastline of South Australia (Figure 8b, d). The agreement habitat suitability surface overlapped with $24 \%$ and $70 \%$ of modern distribution points for $C$.

rhomboidea and C. oblonga, respectively. Indeed, species distribution modelling supports the persistence of suitable habitat for both species since the LGM within the estimated glacial extent of both temperate and steppe vegetation types (individual projections for each GCM are provided in Supporting Information 1, Figure S4). Significantly, areas of high probability of suitable habitat during the LGM coincided with centres of high genetic diversity for both species (Figure 8).

\section{Discussion}

The strong among population genetic structuring of two widespread, dry adapted conifer species together with the species distribution models supports the long-term persistence of these species in multiple temperate forest refugia across the full extent of the modern eastern Australian temperate zone. Spatial genetic structuring is evident despite the wind dispersal of the pollen mediated chloroplast and nuclear markers in Callitris (Sakaguchi et al., 2014). This is likely due to poor gene flow of both pollen and seed over the highly disjunct distribution of each species. Similar strong genetic structuring has been observed in other Cupressaceae conifers with fragmented populations (e.g. Zhang et al., 2005). Geographically restricted haplotypes support the presence of glacial refugia for $C$. rhomboidea and $C$. oblonga within both the northern and southern temperate zones despite only the northern temperate zone being thought to have maintained a forest biome during the LGM (Hope et al., 2004). In fact, the major genetic divergence in the most widespread species, C. rhomboidea, coincided almost exactly with the boundary between these zones. Genetic data along with species distribution modelling suggests that many areas where the species occurs today likely remained as suitable habitat, and/or were close to suitable habitat on the now submerged continental shelf, through the major climatic changes from the dry and cold LGM to the present.

\section{Glacial refugia in the northern temperate zone}

In both species, the northern temperate zone was genetically diverged from populations in the southern temperate zone reflecting their long isolation. Molecular dating showed that timing 
of divergences between northern and southern populations were far older than the Last Glacial Maximum. In C. oblonga, C. oblonga subsp. parva diverged approximately 2.45-2.66 mya and the more southerly distributed subspecies, C. oblonga subsp. corangensis and $C$. oblonga subsp. oblonga diverged approximately 1.08-1.21 mya. The major divergence in $C$. rhomboidea was younger with the 'northern' lineage estimated to have diverged 0.43-0.47 mya from the 'southern' lineage. The genetic divergence between northern and southern temperate zones is consistent with other studies across a range of biota including both plants and animals (see review in Milner et al., 2012). Although it is difficult to assign specific events to explain the divergences observed, partly due to a lack of evidence beyond the last glacial cycle (approximately 125 ka ago) (Ayliffe et al. 1998), it is consistent with a longterm trend towards an increasing dominance of flammable Eucalyptus woodlands and the retraction of fire-sensitive rainforest elements through the Pleistocene (Sniderman 2011; Kershaw et al. 1994).

Within the northern temperate zone there was significant geographic structuring in both species with geographically restricted chloroplast and ITS haplotypes suggesting multiple refugia within this zone. In C. oblonga subsp. parva, two diverged ITS haplotypes suggest the genetic isolation of northern and southern populations. However, sampling of a greater part of the range of this subspecies is required to discern the distribution of these haplotypes and its significance. In C. rhomboidea, while modelled LGM habitat was largely continuous, geographically restricted ITS and chloroplast haplotypes support the presence of discrete temperate forest refugia in the Mallacoota area in far eastern Victoria, south-east NSW, the Sydney region, northern NSW and SE Queensland. Similar genetic evidence for refugia in these areas have been observed in other widespread temperate species such as Hardenbergia violacea (Larcombe et al. 2011), Tasmannia lanceolata (Worth et al., 2010) and Atherosperma moschatum (Worth et al., 2011). As more or less continuous suitable modelled habitat has been maintained to the present, poor dispersal of $C$. rhomboidea and confinement 'islands' of habitat with low-fire frequency has likely led to the development and maintenance of a strong phylogeographic structure at least at the coarse scale. Finer scale sampling, especially on mainland Australia would be useful to reveal the exact phylogeographic boundaries and level of admixture of ITS haplotypes.

Two populations near the south-east Queensland coast (Beerwah State Forest and Brown Lake on Stradbroke Island) are particularly notable based on their high number of unique ITS haplotypes and haplotype richness, higher than any other populations studied in the species 
(Figure S3) suggesting that this region has maintained relatively large population sizes over time. Similar findings of highest genetic diversity in northern populations has been observed in another southern hemisphere Cupressaceae conifer, Austrocedrus chilenis (Pastorino et al. 2004). This areas importance as climate refugia for temperate species is supported by evidence for continuous wet climate on Stradbroke Island for the past 40 kya (Tibby et al., (2017).

\section{Glacial refugia in the southern temperate zone}

The southern temperate region was found to harbour three distinct geographically restricted lineages in C. rhomboidea, while genetic data supports the presence of $C$. oblonga in Tasmania for multiple glacial-interglacial cycles. Both species were able to persist in (i) suitable climate for these species as predicted by species distribution modelling to have occurred in inland Victoria and South Australia and along the coastline and the submerged continental shelves near Kangaroo Island and eastern Tasmania; and/or (ii) within the glacial steppe vegetation in suitable warm microsites or even as a component of non-analogue LGM vegetation, that is, occurring in now extinct environments outside their modern niche (Worth et al. 2014). This is made more plausible given that, D’Costa et al. (1989) recorded Cupressaceae pollen, almost certainly represnting Callitris, at levels of up to $10 \%$ at Tower Hill in southern Victoria as part of a non-analogue glacial steppe dominant in the area approximately 20,000 years ago.

current existing niche.

The genetic divergence of mainland Tasmanian populations of $C$. rhomboidea and $C$. oblonga show that these species arose from local refugia during the Holocene. The lack of genetic diversity within C. oblonga in Tasmania is consistent with its narrower range and probable genetic bottlenecking over multiple glacial cycles. In contrast, Tasmanian populations of $C$. rhomboidea displayed genetic diversity within both ITS and chloroplast markers, possibly a result of larger effective population sizes in multiple refugia along the eastern Tasmanian coast. Long-term persistence of these species in eastern mainland Tasmania is also supported by the high local endemism of plants within their ranges (Kirkpatrick \& Brown, 1984) and LGM pollen data from the Freycinet Peninsula for the persistence of temperate dry sclerophyll plants (Mackenzie \& Moss, 2014) including Callitris pollen at 2-3\% levels. Given the poor dispersal of Callitris pollen (Luly, 2001), as demonstrated by the fact that Callitris pollen is nearly completely absent from pollen cores 
sampled from eastern Tasmania but outside the range of either Callitris species (e.g. Jones, Thomas, \& Fletcher, 2017; Thomas \& Kirkpatrick, 1996), this level of pollen is likely to represent a regional presence and/or the local survival of scattered trees. Species distribution modelling suggests that both species have remained remarkably close to LGM refugia that occurred on the modern and LGM coast suggesting very limited dispersal of these species in the post-glacial as is also likely to explain some modern distribution gaps in the species range (Kirkpatrick and Fowler 1998).

While considered a dispersal route for biota between Tasmania and mainland Australia during glacials (Bridgewater, 1976), the finding of unique C. rhomboidea chloroplast and ITS variation within populations on Flinders Island of the Furneaux group of islands supports a refugium in situ in the exposed Bass Strait during the LGM. Populations of another temperate tree, Eucalyptus globulus, is also genetically distinctive on Flinders Island (Yeoh et al., 2012). Both these cases demonstrate that while Bass Strait was likely to have been dominated by steppe during glacial periods (Hope 1978), temperate species was also able to persist in some areas including near the hills that now form that Furneaux islands.

The genetic divergence of the C. rhomboidea populations in the wetter parts of South Australia and the Grampians in western Victoria contributes to an accumulating body of evidence as to the distinct nature of the temperate flora in these regions. For example, both the Grampians and Kangaroo Island/Mt Lofty Ranges are areas of high plant endemism and richness (Guerin et al., 2016)(Crisp et al., 2001) and previous studies of widespread plant taxa have found that these regions contains unique genetic lineages including Hardenbergia violacea (Larcombe et al. 2011), the genus Correa (French, Brown, \& Bayly, 2016), Tasmannia lanceolata (Worth et al., 2010) and Eucalyptus globulus subsp. bicostata (Freeman et al. 2001; Jones et al. 2013).

\section{Conservation of Callitris}

The high genetic structuring of both species has important consequences for their conservation, as the loss of populations is likely to result in a reduction of genetic diversity. This is particularly the case for C. rhomboidea where $60 \%$ of ITS haplotypes were found in no more than one population. There is widespread evidence of both historical and more recent range contractions of both Callitris species due to increases in fire frequency, a threat that is likely to intensify under warmer and more seasonal climates in the future. This is because, although $C$. rhomboidea has the ability to regenerate both immediately after fire and 
during fire free intervals via seed stored in semi-serotinous cones (Ladd et al. 2013), fires more frequent than approximately 10 years apart can locally eliminate the species (Thomas, Enright, \& Kenyon, 2001). Pollen records from the Little Desert National Park in far northwest Victoria show declines of $C$. rhomboidea pollen with an increase in charcoal frequency (Thomas, Enright, \& Kenyon, 2001), while the species has declined since European settlement on Furneaux Islands (Ladd et al. 1992; Hahs, Enright, \& Thomas, 1999), even becoming extirpated on one minor island of this group (Harris \& McKenny, 1999). More recent fires have resulted in near elimination from parts of the Grampians after two consecutive fires within a four-year period (Enright, Miller, \& Crawford, 1994). For C. oblonga, in both Tasmania and NSW, fire is a threat to remaining stands particularly on private land (Threatened Species Section, 2016). If local extinction occurs, both species are unlikely to be able to re-occupy a site because of poor seed dispersal (Harris \& Kirkpatrick 1991b).

\section{Conclusion}

Overall, range-wide genetic data from both chloroplast and nuclear genomes have revealed that the highly disjunct distributions of two Callitris species have arisen via the interplay between fragmentation and poor dispersal over hundreds of thousands of years during the Pleistocene glacial-interglacial cycles. Similar to wet forest species that have been studied to date in south-eastern Australia, any glacial-interglacial population expansions have been at regional or local scales rather than range-wide events reported in the Northern Hemisphere. Data from more informative nuclear genetic markers such as microsatellites or RAD-seq, coupled with more intensive sampling, could reveal more fine-scale population dynamics within the major lineages identified. Given the high structuring of genetic diversity in $C$. rhomboidea and C. oblonga keeping fire events at suitably distant intervals of 15-20 years or more should be a priority for their management and conservation.

\section{Acknowledgements}

The authors would like to thank the two anonymous reviewers for their suggestions that helped to improve this paper. We would also like to thank M. J. Bayly, T. Brodribb, R. Pickup, K. Rann, L. Prior, S. Nichols, H. MacDermott and R. W. Worth for collecting samples and assistance in the field. This study was funded by a Forestry and Forest Products Research Institute, Tsukuba, Japan, grant number 201430. 


\section{References}

Bandelt HJ, Forster P \& Röhl A. 1999. Median-joining networks for inferring intraspecific phylogenies. Molecular Biology and Evolution 16: 37-48.

Bouckaert R, Heled J. (2014) DensiTree 2: seeing trees through the forest. bioRxiv, 012401.

Bouckaert RR, Drummond AJ (2017) bModelTest: Bayesian phylogenetic site model averaging and model comparison. BMC Evolutionary Biology 17, 42.

Bowman DMJS \& Harris S. 1995. Conifers of Australia's Dry Forests and Open Woodlands. In 'Ecology of southern conifers'. (Eds N Enright \& R Hill) pp 252-270 (University of Melbourne, Melbourne)

Breiman L. 2001. Random forests. Machine learning 45: 5-32.

Bridgewater PB. 1976. Geographical elements in the flora of Victoria. Australian Journal of Botany 24: 249-264.

Brown MJ \& Duncan F. 1986. The vegetation of the Tasman Peninsula. In Smith, S.J. (Ed.) 1989: Is history enough? Past, present and future use of the resources of the Tasman Peninsula. Royal Society of Tasmania, Hobart: 33-50.

Byrne M \& Moran GF. 1994. Population divergence in the chloroplast genome of Eucalyptus nitens. Heredity 73: 18-28.

Chapple DG, Keogh JS \& Hutchinson MN. 2005. Substantial genetic substructuring in southeastern and alpine Australia revealed by molecular phylogeography of the Egernia whitii (Lacertilia: Scincidae) species group. Molecular Ecology 14: 1279-1292.

Colhoun EA. 2000. Vegetation and climate change during the Last Interglacial-Glacial cycle in western Tasmania, Australia. Palaeogeography, Palaeoclimatology, Palaeoecology 155: 195-209.

Colhoun EA \& Shimeld PW. 2012. Late-Quaternary vegetation history of Tasmania from pollen records.

Costa Silva J, Harrison PA, Wiltshire RJE \& Potts BM. 2018. Evidence that divergent selection shapes a developmental cline in a forest tree species complex. Annals of Botany 122: $181-194$.

Cox CB. 2001. The biogeographic regions reconsidered. Journal of Biogeography 28: 511523.

Crisp, Laffan, Linder, et al. 2001. Endemism in the Australian flora. Journal of Biogeography 28: 183-198.

Cutler DR, Edwards TC, Beard KH, et al. 2007. Random forests for classification in ecology. Ecology 88: 2783-2792.

D'Costa DM, Edney P, Kershaw P \& De Dekker P. 1989. Late Quaternary palaeoecology of Tower Hill, Victoria, Australia. Journal of Biogeography 16: 461-482.

Dellicour S \& Mardulyn P. 2014. SPADS 1.0: a toolbox to perform spatial analyses on DNA sequence data sets. Molecular Ecology Resources 14: 647-651.

Dormann CF, Elith J, Bacher S, et al. 2013. Collinearity: a review of methods to deal with it and a simulation study evaluating their performance. Ecography 36: 27-46.

Dupanloup I, Schneider S \& Excoffier L. 2002. A simulated annealing approach to define the genetic structure of populations. Molecular Ecology 11: 2571-2581. 
Engler R, Guisan A \& Rechsteiner L. 2004. An improved approach for predicting the distribution of rare and endangered species from occurrence and pseudo - absence data. Journal of Applied Ecology 41: 263-274.

Enright NJ, Miller BP \& Crawford A. 1994. Environmental correlates of vegetation patterns and species richness in the northern Grampians, Victoria. Austral Ecology 19: 159168.

Farjon A. 2005. A monograph of Cupressaceae and Sciadopitys. Kew: Royal Botanic Gardens, Kew 643p.. ISBN.

Freeman JS, Jackson HD, Steane DA, et al. 2001. Chloroplast DNA phylogeography of Eucalyptus globulus. Australian Journal of Botany 49: 585-596.

French PA, Brown GK \& Bayly MJ. 2016. Incongruent patterns of nuclear and chloroplast variation in Correa (Rutaceae): introgression and biogeography in south-eastern Australia. Plant Systematics and Evolution 302: 447-468.

Guerin GR, Biffin E, Baruch Z, et al. 2016. Identifying centres of plant biodiversity in South Australia. PloS One 11: e0144779.

Hahs A, Enright NJ \& Thomas I. 1999. Plant communities, species richness and their environmental correlates in the sandy heaths of Little Desert National Park, Victoria. Austral Ecology 24: 249-257.

Harris S \& Brown MJ. 1980. The vegetation of Hellfire Bluff- Cape Bernier, Tasmania. Tasmanian Naturalist 62: 1-14.

Harris S \& Kirkpatrick JB. 1991a. The phytosociology and synecology of Tasmanian vegetation with Callitris. Proceedings of the Royal Society of Tasmania: 179-190.

Harris S \& Kirkpatrick JB. 1991b. The distributions, dynamics and ecological differentiation of Callitris Species in Tasmania. Australian Journal of Botany 39: 187-202.

Harris S \& McKenny H. 1999. Preservation Island, Furneaux Group: Two hundred years of vegetation change. Papers and Proceedings of the Royal Society of Tasmania: 85-102.

Harrison PA, Jones RC, Vaillancourt RE, Wiltshire RJE \& Potts BM. 2014. Unravelling the evolutionary history of Eucalyptus cordata (Myrtaceae) using molecular markers. Australian Journal of Botany 62: 114-131

Hastie T, Tibshirani R \& Friedman J. 2009. Unsupervised learning. In: The elements of statistical learning. Springer, pg. 485-585.

Heled J, Drummond AJ. (2009) Bayesian inference of species trees from multilocus data. Molecular Biology and Evolution 27, 570-580.

Hijmans RJ, Cameron SE, Parra JL, et al. 2005. Very high resolution interpolated climate surfaces for global land areas. International journal of climatology 25: 1965-1978.

Hijmans RJ, van Etten J, Cheng J, et al. 2017. Raster: Geographic Data Analysis and Modeling. R package version 2.3-33; 2016.

Hill K. 1998. Flora of Australia: Ferns, gymnosperms and allied groups. In: Flora, Australia. Bureau of Study, Australian Biological Resources. Melbourne: CSIRO Publishing, 545-596.

Hill RS \& Orchard AE. 1999. Composition and endemism of vascular plants. In: Reid JB, Hill RS HM, ed. Vegetation of Tasmania. Hobart,: ABRS, 89-124.

Hope GS. 1978. The late Pleistocene and Holocene vegetational history of Hunter Island, north-western Tasmania. Australian Journal of Botany 26: 493-514. 
Hope GS. 1994. 15 Quaternary vegetation. History of the Australian vegetation: Cretaceous to recent: 368.

Hope G, Kershaw AP, van der Kaars S, et al. 2004. History of vegetation and habitat change in the Austral-Asian region. Quaternary International 118: 103-126.

Hunter JT. 1999. Vegetation and floristics of Bald Rock and Boonoo Boonoo National Parks. A report to the NSW National parks and Wildlife Service. NPWS, Glen Innes, NSW.

Jones RC, Steane DA, Lavery M, et al. 2013. Multiple evolutionary processes drive the patterns of genetic differentiation in a forest tree species complex. Ecology and Evolution 3: $1-17$.

Jones Z \& Linder F. 2015. Exploratory data analysis using random forests. In: Prepared for the 73rd annual MPSA conference.

Jones PJ, Thomas I \& Fletcher MS. 2017. Long-term environmental change in eastern Tasmania: Vegetation, climate and fire at Stoney Lagoon. The Holocene 27: 1340-1349.

Kearns AM, Joseph L, Toon A, et al. 2014. Australia's arid-adapted butcherbirds experienced range expansions during Pleistocene glacial maxima. Nature Communications 5: 3994.

Kirkpatrick JB \& Brown MJ. 1984. A numerical analysis of Tasmanian higher plant endemism. Botanical Journal of the Linnean Society 88: 165-183.

Kirkpatrick JB \& Fowler M. 1998. Locating likely glacial forest refugia in Tasmania using palynological and ecological information to test alternative climatic models. Biological Conservation 85: 171-182.

Ladd PG, Orchiston DW \& Joyce EB. 1992. Holocene vegetation history of Flinders Island. New Phytologist 122: 757-767.

Ladd PG, Midgley JJ \& Nield AP. 2013. Serotiny in southern hemisphere conifers. Australian Journal of Botany 61: 486-496.

Liaw A \& Wiener M. 2002. Classification and regression by randomForest. $R$ news 2: 18-22.

Luly JG. 1995. Holocene palaeoenvironments at Lake Tyrrell-Response to Sluiter and Parsons. Journal of Biogeography 22: 152-156.

Luly JG. 2001. On the equivocal fate of late Pleistocene Callitris Vent.(Cupressaceae) woodlands in arid south Australia. Quaternary International 83: 155-168.

Luoto M \& Heikkinen RK. 2008. Disregarding topographical heterogeneity biases species turnover assessments based on bioclimatic models. Global Change Biology 14: 483-494.

Mackenzie L \& Moss P. 2014. A late Quaternary record of vegetation and climate change from Hazards Lagoon, eastern Tasmania. Quaternary International 432: 58-65.

McIntosh PD, Eberhard R, Slee A, et al. 2012. Late Quaternary extraglacial cold-climate deposits in low and mid-altitude Tasmania and their climatic implications. Geomorphology 179: 21-39.

Milner ML, Rossetto M, Crisp MD, et al. 2012. The impact of multiple biogeographic barriers and hybridization on species-level differentiation. American Journal of Botany 99: 2045-2057.

Milner ML, Weston PH, Rossetto M, et al. 2015. Biogeography of the Gondwanan genus Lomatia (Proteaceae): vicariance at continental and intercontinental scales. Journal of Biogeography 42: 2440-2451. 
Mogensen L. 2009. The hows and whys of cytoplasmic inheritance in seed plants. American Journal of Botany 83: 383-404.

Mooney, SD, Harrison SP, Bartlein, PJ, Daniau, AL, Stevenson J, Brownlie KC, Buckman S, Cupper M, Luly J, Black M, Colhoun E, D’Costa D, Dodson J, Haberle S, Hope GS, Kershaw P, Kenyon C, McKenzie M. \& Williams N. 2011 Late Quaternary fire regimes of Australasia. Quaternary Science Reviews 30: 28-46.

Moreira A \& Santos MY. 2007. Concave hull: A k-nearest neighbours approach for the computation of the region occupied by a set of points. Proceedings of the international conference on computer graphics theory and applications: 61-68

Nadolny C, Llewellyn LC \& Benson JS. 1993. The biology and management of the Pigmy Cypress Pine (Callitris oblonga) in NSW. NSW National Parks and Wildlife Service.

Nevill PG, Bossinger G, Ades PK. 2010. Phylogeography of the world's tallest angiosperm, Eucalyptus regnans: Evidence for multiple isolated Quaternary refugia. Journal of Biogeography 37: 179-192.

Olson DM, Dinerstein E, Wikramanayake ED, et al. 2001. Terrestrial Ecoregions of the World: A New Map of Life on Earth: A new global map of terrestrial ecoregions provides an innovative tool for conserving biodiversity. BioScience 51: 933-938.

Pastorino MJ, Gallo LA \& Hattemer HH. (2004). Genetic variation in natural populations of Austrocedrus chilensis, a cypress of the Andean-Patagonian Forest. Biochemical Systematics and Ecology, 32: 993-1008.

Pateiro-López B \& Rodrıguez-Casal A. 2010. Generalizing the convex hull of a sample: the R package alphahull. Journal of Statistical software 34: 1-28.

Petit RJ, Mousadik A El \& Pons O. 1998. Identifying populations for consevation on the basis of genetic markers. Conservation Biology 12: 844-855.

Premoli AC, Mathiasen P \& Kitzberger T. 2010. Southern-most Nothofagus trees enduring ice ages: genetic evidence and ecological niche retrodiction reveal high latitude (54 S) glacial refugia. Palaeogeography, Palaeoclimatology, Palaeoecology, 298: 247-256.

Pye MG, Gadek PA \& Edwards KJ. 2003. Divergence, diversity and species of the Australasian Callitris (Cupressaceae) and allied genera: evidence from ITS sequence data. Australian Systematic Botany 16: 505-514.

R Core Team. 2017. R: A language and environment for statistical computing. R Foundation for Statistical Computing, Vienna, Austria. 2016.

Rambaut A. (2012) FigTree v1. 4. Molecular evolution, phylogenetics and epidemiology. Edinburgh, UK: University of Edinburgh, Institute of Evolutionary Biology.

Rambaut A, Suchard M, Xie D, Drummond A. (2016) Tracer v1.6.0, http://tree.bio.ed.ac.uk/software/tracer/.

Rozas J \& Rozas R. 1995. DnaSP, DNA sequence polymorphism: an interactive program for estimating population genetics parameters from DNA sequence data. Computer applications in the biosciences: CABIOS 11: 621-625.

Sakaguchi S, Tsumura Y, Crisp MD, et al. 2014. Genetic evidence for paternal inheritance of the chloroplast in four Australian Callitris species (Cupressaceae). Journal of forest research 19: 244-248.

Samarakoon T, Wang SY \& Alford MH. 2013. Enhancing PCR amplification of DNA from recalcitrant plant specimens using a trehalose-based additive. Applications in plant 
sciences 1: 1200236.

Thom B, Hesp P \& Bryant E. 1994. Last glacial “coastal” dunes in Eastern Australia and implications for landscape stability during the Last Glacial Maximum. Palaeogeography, Palaeoclimatology, Palaeoecology 111: 229-248.

Thomas I, Enright NJ \& Kenyon CE. 2001. The Holocene history of mediterranean plant type communities, Little Desert National Park, Victoria, Australia. The Holocene 11: 691697.

Thomas I \& Kirkpatrick JB. 1996. The roles of coastlines, people and fire in the development of heathlands in northeast Tasmania. Journal of Biogeography 23: 717-728.

Threatened Species Section. 2016. Notesheet for Callitris oblonga subsp. oblonga (south esk pine). Department of Primary Industries, Parks, Water and Environment, Tasmania.

Tibby J, Barr C, Marshall JC, et al. 2017. Persistence of wetlands on North Stradbroke Island (south - east Queensland, A Quaternary science and biogeography. Journal of Quaternary Science 32: 770-781.

Wager S \& Walther G. 2015. Uniform convergence of random forests via adaptive concentration. arXiv preprint arXiv:1503.06388.

Wahid N, González-Martínez SC, El Hadrami I, et al. 2006. Variation of morphological traits in natural populations of maritime pine (Pinus pinaster Ait.) in Morocco. Annals of Forest Science 63: 83-92.

Williams M, Cook E, van der Kaars S, et al. 2009. Glacial and deglacial climatic patterns in Australia and surrounding regions from 35000 to 10000 years ago reconstructed from terrestrial and near-shore proxy data. Quaternary Science Reviews 28: 2398-2419.

Worth JRP, Jordan GJ, Marthick JR, et al. 2010. Chloroplast evidence for geographic stasis of the Australian bird-dispersed shrub Tasmannia lanceolata (Winteraceae). Molecular Ecology 19: 2949-2963.

Worth JRP, Marthick JR, Jordan GJ, et al. 2011. Low but structured chloroplast diversity in Atherosperma moschatum (Atherospermataceae) suggests bottlenecks in response to the Pleistocene glacials. Annals of Botany 108: 1247-1256.

Wright S, Keeling J \& Gillman L. 2006. The road from Santa Rosalia: a faster tempo of evolution in tropical climates. Proceedings of the National Academy of Sciences of the United States of America 103: 7718-7722.

Xu T \& Hutchinson MF. 2013. New developments and applications in the ANUCLIM spatial climatic and bioclimatic modelling package. Environmental Modelling \& Software 40: 267-279.

Xu Y, Woeste K, Cai N, et al. 2016. Variation in needle and cone traits in natural populations of Pinus yunnanensis. Journal of forestry research 27: 41-49.

Yeoh SH, Bell JC, Foley WJ, et al. 2012. Estimating population boundaries using regional and local-scale spatial genetic structure: an example in Eucalyptus globulus. Tree Genetics \& Genomes 8: 695-708.

Yokoyama Y, Lambeck K, De Deckker P, et al. 2000. Timing of the Last Glacial Maximum from observed sea-level minima. Nature 406: 713.

Zhang Q, CHIANG TY, George M, et al. 2005. Phylogeography of the Qinghai -Tibetan Plateau endemic Juniperus przewalskii (Cupressaceae) inferred from chloroplast DNA sequence variation. Molecular Ecology 14: 3513-3524. 

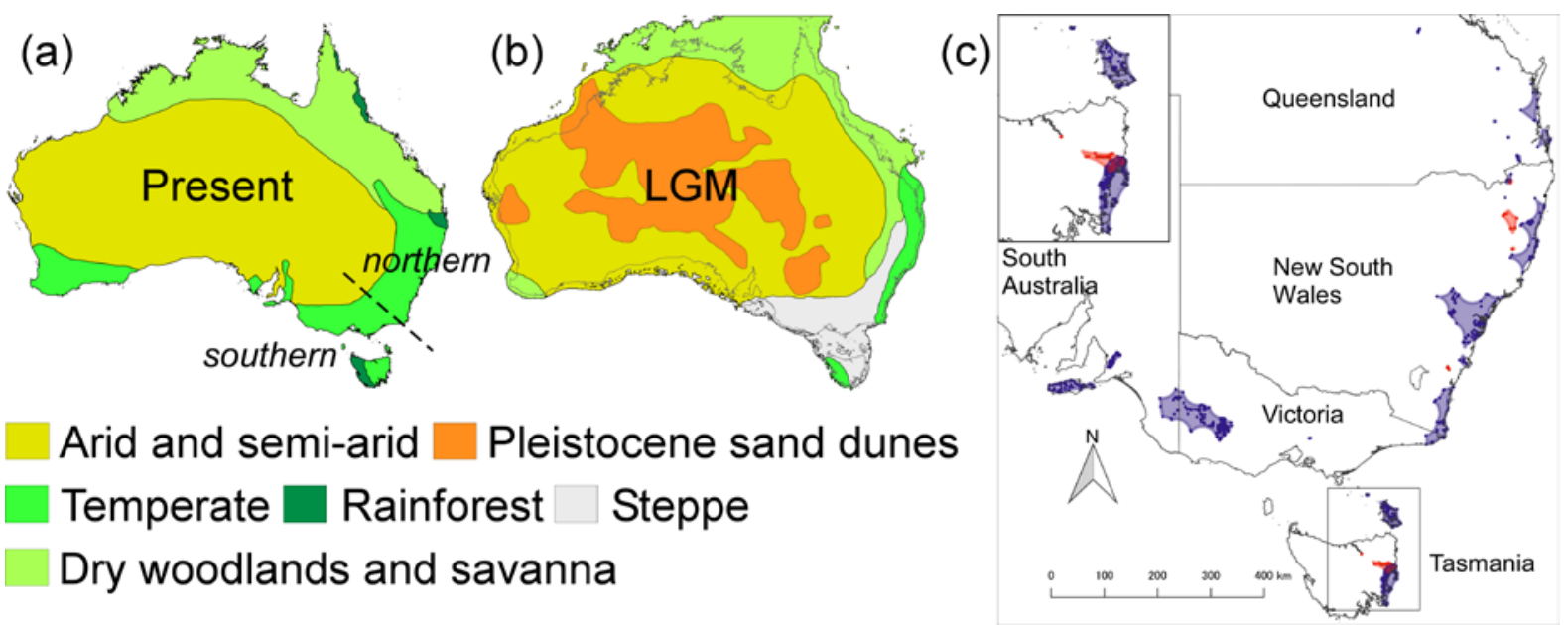

Figure 1. (a,b) During the Pleistocene glacials, the temperate zone persisted in the northern part of the modern eastern Australian temperate zone near the coast and was replaced by steppe in the southern part apart from western Tasmania (based on pollen data (Hope et al., 2004)). The line in (a) delineates the boundary between the 'northern' temperate zone where temperate vegetation is thought to have persisted during glacials and the 'southern' temperate zone which is thought to have been dominated by a now extinct steppe type treeless vegetation. The modern and Last Glacial Maximum distribution of major biomes in Australia modified from (Kearns et al., 2014). (c) The current distribution of Callitris rhomboidea (blue polygons) and C. oblonga (red polygons) in southeastern Australia. 


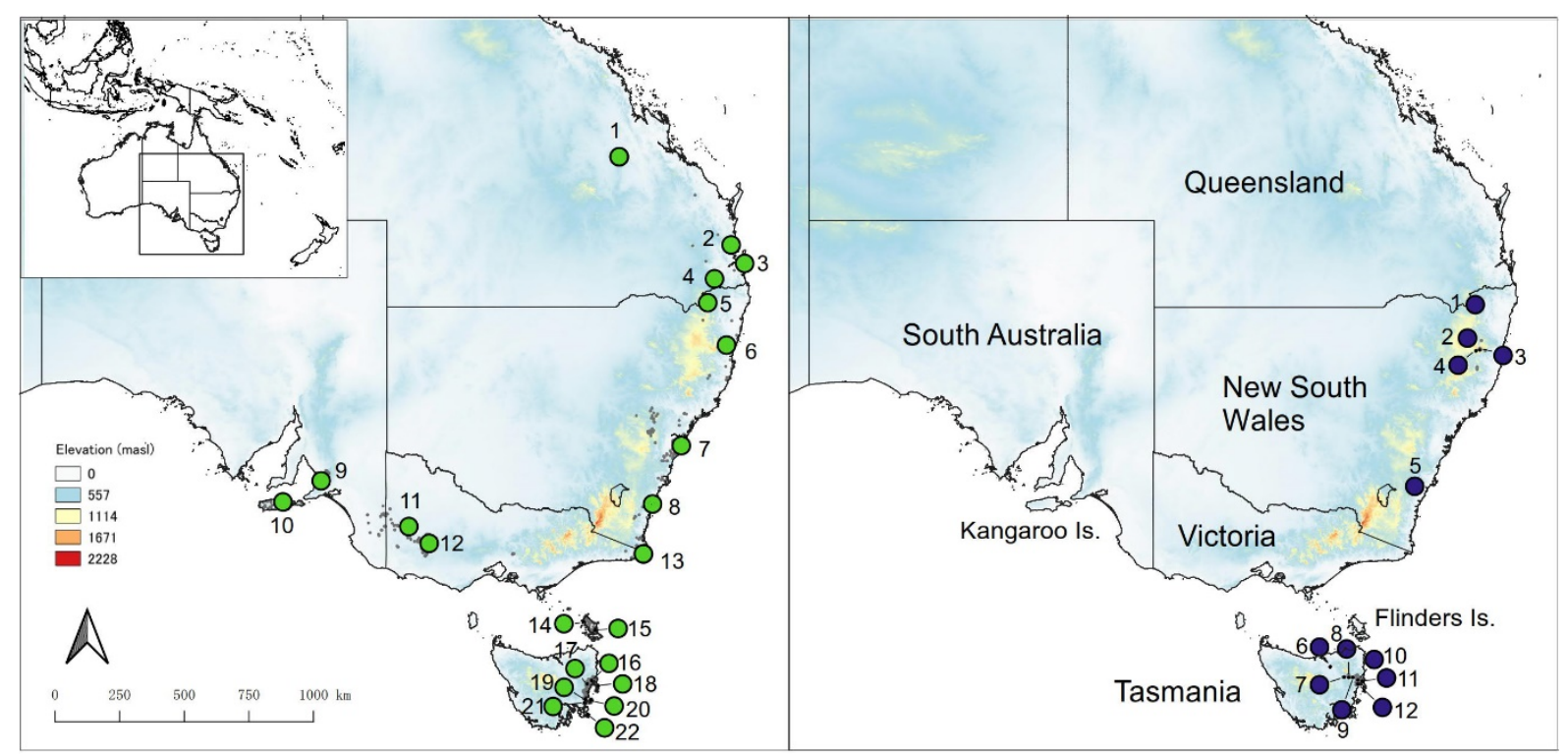

Figure 2 The locations of the 22 sampled populations of Callitris rhomboidea and 12 populations of $C$. oblonga including all three subspecies. Numbers correspond to the sampled populations detailed in Supplementary Material Table S1 and S2. Also shown is a digital elevation model where warmer colours correspond to higher elevations above sea level (m.a.s.l). The known distribution of both species is shown as small grey dots. 


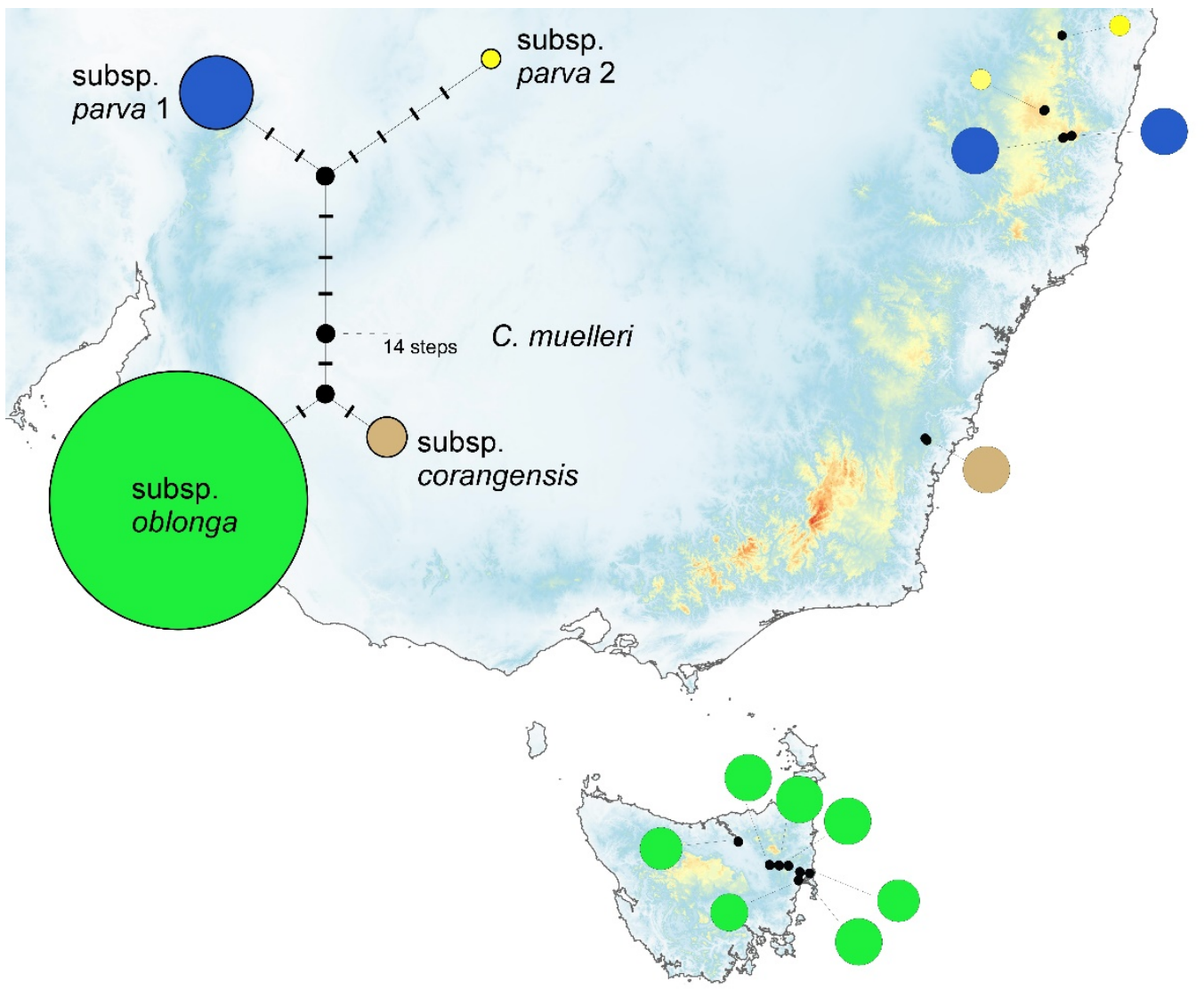

Figure 3. Distribution of four internal transcribed spacer (ITS) phased haplotypes observed in 12 populations of Callitris oblonga representing all three subspecies with the sister species C. muelleri shown as an outgroup. The size of the circles is proportional to their frequency and the colours match those of a median joining network of the three chloroplast haplotypes in the top left corner. The branch lengths and dashes in the median joining network indicate the number of DNA polymorphisms separating the haplotypes. 


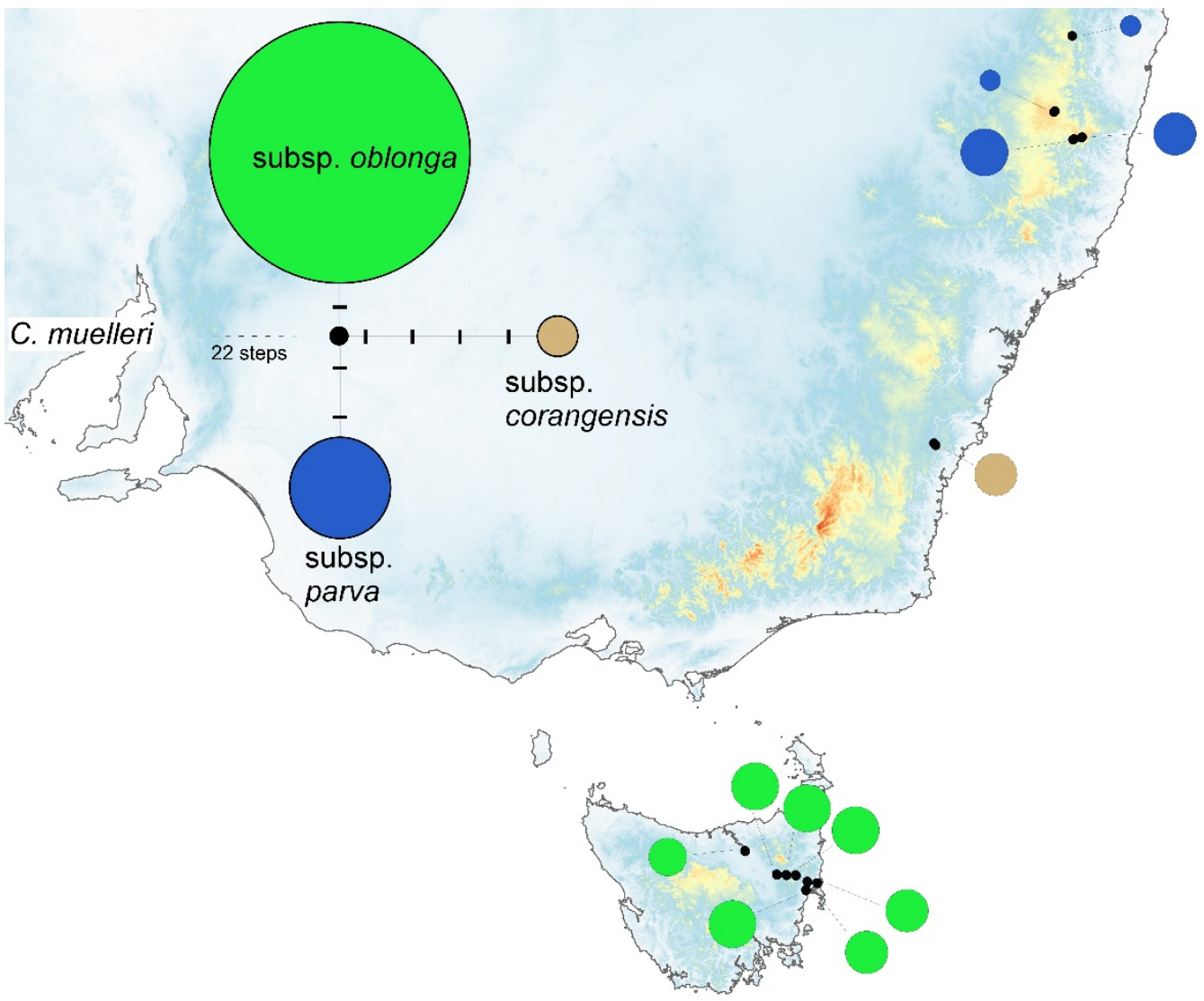

Figure 4. Distribution of the three chloroplast haplotypes observed in 12 populations of Callitris oblonga representing all three subspecies with the sister species $C$. muelleri shown as an outgroup. The size of the circles is proportional to their frequency and the colours match those of a median joining network of the three chloroplast haplotypes in the top left corner. The branch lengths and dashes in the median joining network indicate the number of DNA polymorphisms separating the haplotypes. 


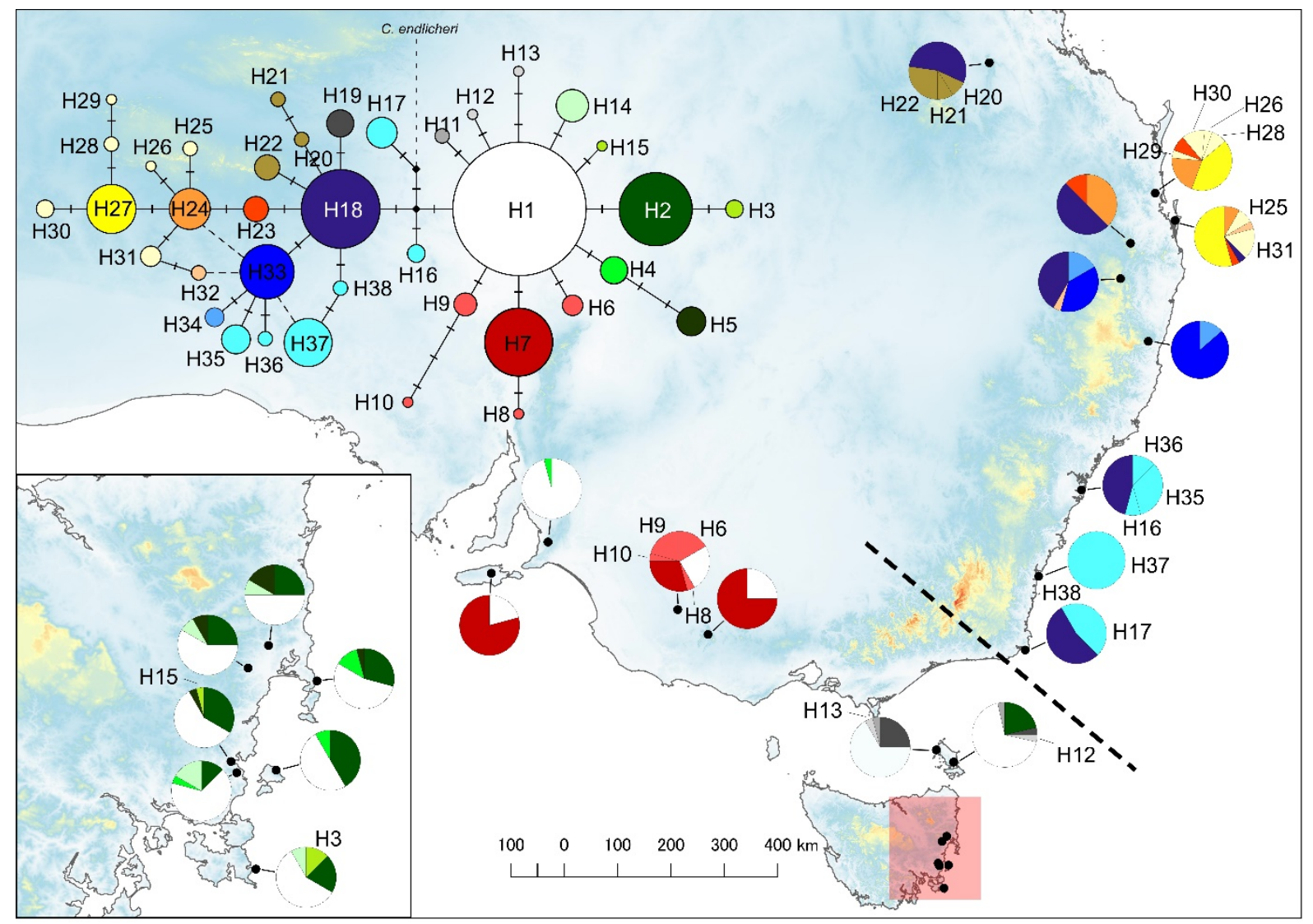

Figure 5. Distribution of the 38 internal transcribed spacer phased haplotypes observed in 22 populations of Callitris rhomboidea with $C$. endlicheri used as an outgroup. The inset map shows the distribution of ITS based haplotypes in eastern Tasmania. Haplotypes are coloured the same based on their geographic location while haplotypes found in one population are indicated with numbers referring to the haplotype number in the median joining network. The size of the circles is proportional to haplotype frequency and branch lengths and dashes indicate the number of DNA polymorphisms separating the haplotypes. ITS haplotype based spatial analysis of molecular variance (SAMOVA) groups I and II when $K=2$ are divided by a line separating group I populations in Tasmania and South Australia/ western Victoria and group II north of eastern Victoria. 


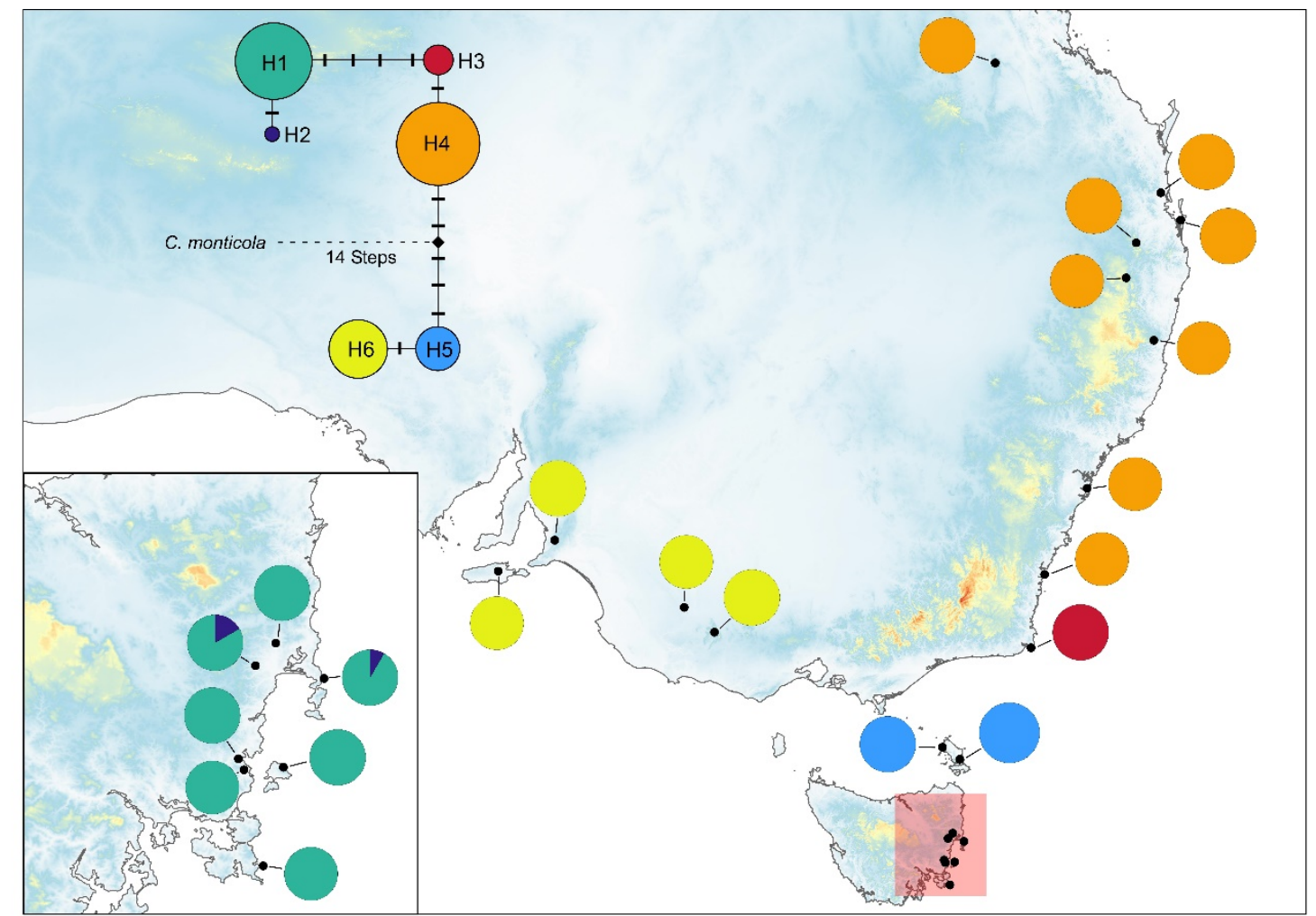

Figure 6. Median joining network of the six chloroplast haplotypes found in 22 populations Callitris rhomboidea with C. monticola used an ougroup. The size of the circles is proportional to haplotype frequency. The haplotype geographic distribution is represented by colours. 

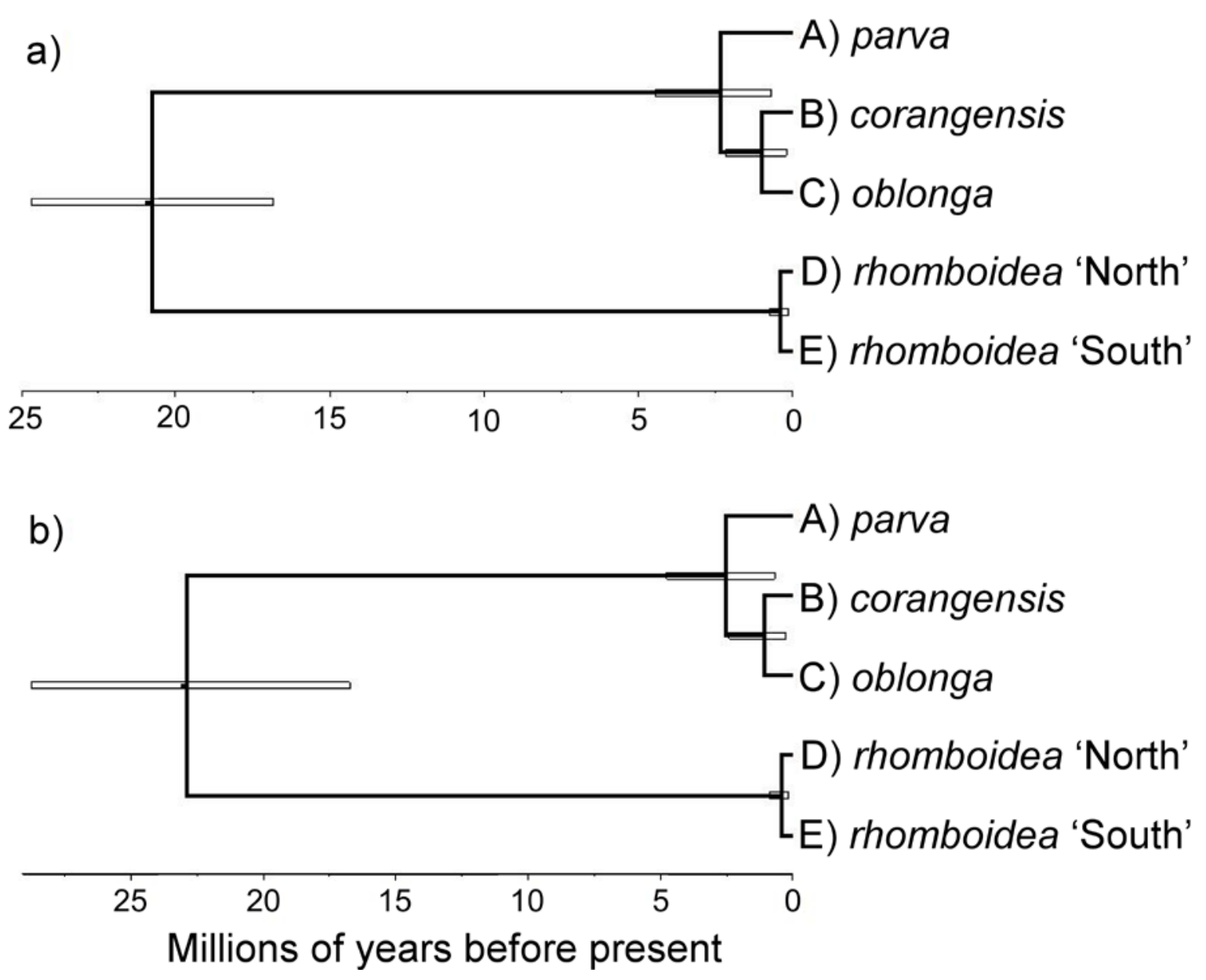

Figure 7. Coalescent based phylogenetic relationship among the Calitris subspecies inferred from ITS and cpDNA sequences. Two different divergence date priors were used: a) a younger date (21.2 mya), and b) an older date (23.7 mya). Scale bars are in million years before present. Uncertainty in node ages are shown as 95\% HPD with a blue bar. Letters correspond to the five genetic groupings of Callitris used in the current study: A, C. oblonga subsp. parva; B, C. oblonga subsp. corangensis; C, C. oblonga subsp. oblonga; D, C. rhomboidea North; E, C. rhomboidea South. 


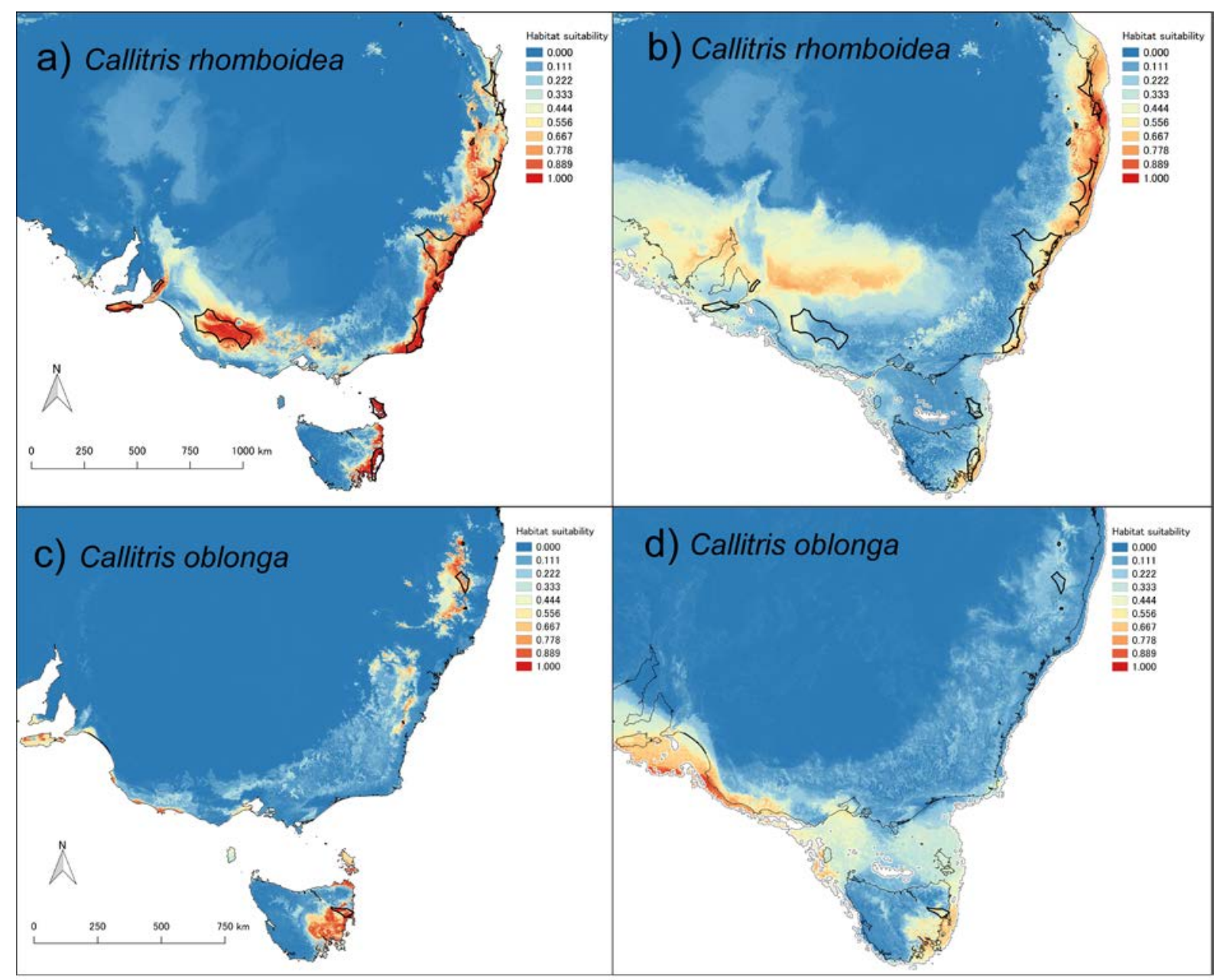

Figure 8. Predicted distribution of suitable habitat for Callitris rhomboidea and Callitris oblonga under modern (1960-1990) (a,c) and Last Glacial Maximum (ca. 22 kya BP) climates (b, d). The distribution of suitable habitat for the LGM represents the average predictions derived from three GCMs. Habitat suitability ranges from 1 (red) indicating high probability of suitable habitat to zero (blue) being unsuitable habitat. The known distribution of each species is represented by alpha hulls (black polygons). 
Table 1. Summary of the genetic diversity observed across the range of Callitris oblonga and $C$. rhomboidea at both the internal transcribed spacer (ITS) and three chloroplast sequences (trnH-psbA, psbT-psbN and rpl16).

\begin{tabular}{|c|c|c|c|c|c|}
\hline Species & $\begin{array}{c}\text { Marker } \\
\text { (aligned } \\
\text { bp) }\end{array}$ & SNPs & Indels & $\begin{array}{l}\text { Nucleotide } \\
\text { Diversity } \\
\text { (St. Dev) }\end{array}$ & $\begin{array}{l}\text { Haplotype } \\
\text { Diversity }\end{array}$ \\
\hline \multirow[t]{2}{*}{ C.oblonga } & $\begin{array}{l}\text { ITS } \\
(1112)\end{array}$ & 10 & 2 & $\begin{array}{c}0.00224 \\
(0.00017)\end{array}$ & 0.569 \\
\hline & $\begin{array}{c}\text { cpDNA } \\
\text { (1381) }\end{array}$ & 2 & 4 & $\begin{array}{c}0.00046 \\
(0.00004)\end{array}$ & 0.554 \\
\hline \multirow[t]{2}{*}{ C. rhomboidea } & $\begin{array}{l}\text { ITS } \\
(1185)\end{array}$ & 40 & 2 & $\begin{array}{c}0.00239 \\
(0.00006)\end{array}$ & 0.840 \\
\hline & $\begin{array}{c}\text { cpDNA } \\
\text { (1483) }\end{array}$ & 7 & 3 & $\begin{array}{c}0.00172 \\
(0.00006)\end{array}$ & 0.704 \\
\hline
\end{tabular}

Table 2. Node support and mean estimated node ages in million years for Callitris subspecies estimated using STARBEAST2. For each clade node support and node age are given in percentages and as mean and 95\% HPD.

\begin{tabular}{llll}
\hline Divergence date & Clade $^{\mathbf{1}}$ & Node support (\%) & Mean node age (mya) \\
\hline Younger (21.2 mya) & $\mathrm{ABC}+\mathrm{DE}$ & 100 & $20.77(16.84 ; 24.67)$ \\
& $\mathrm{A}+\mathrm{BC}$ & 100 & $2.45(0.71 ; 4.46)$ \\
& $\mathrm{B}+\mathrm{C}$ & 91 & $1.08(0.21 ; 2.16)$ \\
& $\mathrm{D}+\mathrm{E}$ & 100 & $0.43(0.17 ; 0.75)$ \\
Older (23.7 mya) & $\mathrm{ABC}+\mathrm{DE}$ & 100 & $22.90(16.74 ; 28.77)$ \\
& $\mathrm{A}+\mathrm{BC}$ & 100 & $2.66(0.70 ; 4.76)$ \\
& $\mathrm{B}+\mathrm{C}$ & 91 & $1.21(0.26 ; 2.41)$ \\
& $\mathrm{D}+\mathrm{E}$ & 100 & $0.47(0.18 ; 0.85)$
\end{tabular}

${ }^{1}$ Letters correspond to the five genetic groupings of Callitris used in the current study: $\mathrm{A}, C$. oblonga subsp. parva; B, C. oblonga subsp. corangensis; C, C. oblonga subsp. oblonga; D, C. rhomboidea North; E, C. rhomboidea South. 
